\title{
Review: newer drugs have not yet been shown to be better than clozapine for schizophrenia
}

Tunainen A, Wahlbeck K, Gilbody SM. Newer atypical antipsychotic medication versus clozapine for schizophrenia. Cochrane Database Syst Rev 2000;(3):latest version 20 Feb 2000.

\author{
QUESTION: In patients with schizophrenia, how do the efficacy and safety of newer \\ antipsychotic drugs compare with that of clozapine?
}

\section{Data sources}

Studies were identified by searching Biological Abstracts/BIOSIS (to 1999), the Cochrane Library, EMBASE/Excerpta Medica (to 1998), Medline (to 1999), LILACS (January 1998), PsycLIT/PsycINFO (to 1999), reference lists, and conference proceedings and by contacting authors and drug companies.

Sources of funding: Finnish National Research and Development Centre for Welfare and Healt (STAKES) and Finnish Medical Society.

For correspondence: Dr A Tuunainen, Department of

Psychiatry, University of Helsinki, PO Box 320, FIN-00029 Huch, Finland. Fax +3589 47181316.

\section{Study selection}

Studies were selected if they were randomised controlled trials (RCTs) that compared newer antipsychotic drugs with clozapine in patients with schizophrenia or other schizophrenia like psychoses.

\section{Data extraction}

2 reviewers independently assessed the quality of study methods and extracted data on patient characteristics, drug regimen, trial duration, and outcomes. Disagreements were resolved by discussion.

\section{Main results}

8 blinded RCTs (795 patients) met the selection criteria. Follow up ranged from 4-18 weeks (mean 8.8 wks).
Sample sizes ranged from 20-273 patients (mean 107 patients). The data for all atypical drugs (risperidone, remoxipride, zotepine, and olanzapine) were pooled in the comparisons with clozapine. Newer atypical antipsychotic drugs and clozapine did not differ in the number of patients who had clinically significant improvement (5 RCTs), had deterioration in mental state or relapse (6 RCTs), left the study early (6 RCTs), or were dissatisfied with treatment (3 RCTs). Negative and positive symptom scores did not differ between groups. Newer atypical antipsychotic drugs led to less fatigue, nausea/ vomiting, orthostatic dizziness, and hypersalivation but to more extrapyramidal symptoms than clozapine (table). Differences were not statistically significant for libido decrease, dry mouth, seizures, hypersomnia, sedation/ drowsiness, or insomnia.

\section{Conclusion}

In patients with schizophrenia, newer drugs have not yet been shown to be better than clozapine.

Newer atypical antipsychotic drugs $v$ clozapine for schizophrenia*

\begin{tabular}{|c|c|c|c|c|c|}
\hline \multirow[b]{2}{*}{ Outcomes at mean 8.8 weeks } & \multirow[b]{2}{*}{ Number of RCTs } & \multicolumn{2}{|c|}{ Weighted event rates } & \multirow[b]{2}{*}{$\operatorname{RRR}(95 \% \mathrm{Cl})$} & \multirow[b]{2}{*}{ NNT (Cl) } \\
\hline & & Newer drugs & Clozapine & & \\
\hline Fatigue & 1 & $28 \% \dagger$ & $51 \% \dagger$ & $45 \%$ (4 to 69$)$ & 5 (3 to 32$)$ \\
\hline Nausea/vomiting & 2 & $6 \%$ & $14 \%$ & $58 \%(8$ to 81$)$ & $13(7$ to 84$)$ \\
\hline Orthostatic dizziness & 2 & $4.5 \%$ & $13 \%$ & $65 \%(15$ to 85$)$ & 13 (7 to 59$)$ \\
\hline \multirow[t]{2}{*}{ Hypersalivation } & 1 & $2 \% \dagger$ & $29 \% \dagger$ & $92 \%(69$ to 98$)$ & 4 (3 to 6$)$ \\
\hline & & & & RRI (Cl) & NNH (Cl) \\
\hline Extrapyramidal symptomsł & 5 & $25 \%$ & $7.4 \%$ & $255 \%$ (79 to 606$)$ & $6(4$ to 10$)$ \\
\hline
\end{tabular}

${ }^{*} \mathrm{RCTs}=$ randomised controlled trials. Other abbreviations defined in glossary; RRR, RRI, NNT, NNH, and Cl calculated from data in article. †Event rates not weighted. $\ddagger$ Excludes the study of olanzapine.

\section{COMMENTARY}

The review by Tuunainen et al suggests that novel antipsychotic agents, in the aggregate, may be as effective as clozapine. The evidence, however, is limited, incomplete, and potentially misleading.

All 8 studies compared clozapine with newer agents that vary greatly in pharmacology, clinical properties, and commercial availability, ${ }^{1}$ which strains the credibility of a pooled meta-analysis. Moreover, the concept of a class of similar "atypical antipsychotics" is, arguably, based largely on wishful thinking and marketing efforts.

In addition, no analysed study was actually "controlled," as with a placebo or standard neuroleptic. Instead, all involved A versus B comparisons, which can yield misleading impressions of "not different" rather than provide evidence for equiefficacy. Such comparisons are particularly problematic in chronically psychotic patients who have typically small treatment responses, and the presence of other factors that increase heterogeneity (eg, multiple drugs, diagnostic types, or study sites; unreliable or dichotomous $v$ continuous measures). Such problems are only partly resolved by achieving nominal statistical power to rule out differences. Moreover, testing the implicit assumption that apparent equiefficacy implies clinical superiority to standard agents requires direct and equitably dosed, new versus old drug comparisons.

Finally, the short term trials did not test for long term effectiveness-the critically relevant outcome in which clozapine has proved superior to other agents, with increasing separation from standard neuroleptics over months of treatment. ${ }^{2}$

In short, the case for equiefficacy-let alone superiority-of any newer antipsychotic agent to clozapine or to standard neuroleptics remains unproved. The long term general medical safety and long term effectiveness of newer antipsychotics require further study. Nevertheless, the relative ease of use of these agents makes their use appropriate before considering clozapine for poorly responsive patients.

Ross J Baldessarini, MD Harvard Medical School; McLean Division of Massachusetts General Hospital Boston, Massachusetts, USA

1 Baldessarini RJ, Tarazi FI. Drugs and the treatment of psychiatric disorders: antipsychotic and antimanic agents. In: Hardman JG, Limbird LE, Molinoff PB, et al, editors. Goodman E Gilman's the pharmacological basis of therapeutics. 10th edition. New York: McGraw-Hill Press, in press.

2 Wahlbeck K, Cheine M, Essali A, et al. Evidence of clozapine's effectiveness in schizophrenia: a systematic review and meta-analysis of randomized trials. Am J Psychiatry 1999;156:990-9.

3 Baldessarini RJ, Frankenburg FR. Clozapine. A novel antipsychotic agent. N Engl J Med 1991;324:746-54 